\title{
El precio de la autonomía sindical durante la Transición española: el caso de la Unión Sindical Obrera en la provincia de Cádiz
}

\begin{abstract}
Resumen
Este artículo analiza la evolución de la Unión Sindical Obrera en la provincia de Cádiz (España) durante los primeros años de Transición (1976-1981). Esta organización pasó en pocos años de ser la segunda fuerza sindical en España, detrás de Comisiones Obreras, a ocupar un papel secundario en la arena sindical. A partir de testimonios orales de sindicalistas en diferentes sectores industriales se reconstruyen los marcos, los dilemas y los conflictos internos de dicha organización sindical en el periodo que ha sido mencionado. Este análisis permite cubrir lagunas sobre una de las organizaciones sindicales que han sido menos estudiadas en la historiografía y en la sociología españolas. Asimismo, permite identificar los factores que han propiciado, históricamente, la hegemonía de los sindicatos mayoritarios a escala estatal. Finalmente, permite comprender cómo las representaciones sobre la autonomía sindical y el intercambio político juegan un papel importante en la configuración de la estrategia sindical en diferentes niveles.
\end{abstract}

Palabras clave: Unión Sindical Obrera. Sindicato. Autonomía Sindical. Transición Española. Intercambio Político.

\section{Eva Bermúdez-Figueroa}

Doctora en Sociología por la Universidad Pablo de Olavide (UPO). Profesora de la Universidad de Cádiz (UCA). Cádiz - ESPANHA

eva.bermudez@uca.es orcid.org/0000-0002-1838-6904

\section{Julio Pérez Serrano}

Doctor en Historia por la Universidad de Cádiz (UCA). Profesor de la Universidad de Cádiz (UCA). Cádiz - ESPANHA julio.perez@uca.es orcid.org/0000-0001-7644-4255

\section{Beltran Roca}

Doctor en Antropología Social por la Universidad de Sevilla (US). Profesor de la Universidad de Cádiz (UCA). Cádiz - ESPANHA

beltran.roca@uca.es orcid.org/0000-0001-5534-7843

\section{Para citar este artículo:}

BERMÚDEZ-FIGUEROA, Eva; PÉREZ SERRANO, Julio; ROCA, Beltran. El precio de la autonomía sindical durante la Transición española: el caso de la Unión Sindical Obrera en la provincia de Cádiz. Tempo e Argumento, Florianópolis, v. 11, n. 27, p. 359 - 386, maio/ago. 2019. 


\section{The price for union autonomy during the Spanish Transition: the case of the Workers' Syndical Union in the province of Cádiz}

\begin{abstract}
This article analyses the development of the Worker Labour Union in the province of Cádiz (Spain) during the first years of the Transition (1976-1981). This organisation passed in a few years from being the second most important trade union in Spain, after Workers Commissions, to play a secondary role in the labour arena. Drawing on oral testimonies of union organisers from different industries, the article reconstructs the frames, dilemmas and internal conflicts of this labour organisation during such a period. This analysis allows to fill in the historiographic and sociological gap about this trade union. In addition, it allows to identify the factors that have historically favoured the hegemony of the two Spanish major trade unions. Finally, the article contributes to understand how representations on trade union autonomy and political exchange play an important role in the making of trade union strategy at different scales.
\end{abstract}

Keywords: Unión Sindical Obrera. Trade Union. Trade Union Autonomy. Spanish Transition. Political Exchange.

\section{O preço da autonomia sindical durante a Transição Espanhola: o caso da União Sindical dos Trabalhadores na Província de Cádiz}

\begin{abstract}
Este artigo analisa a evolução do Sindicato dos Trabalhadores na província de Cádiz (Espanha) durante os primeiros anos de transição (1976-1981). Em apenas alguns anos, essa organização tornou-se a segunda força sindical na Espanha, atrás das Comissões de Trabalhadores, a ocupar um papel secundário na arena sindical. Com base em testemunhos orais de sindicalistas em diferentes setores industriais, os marcos, dilemas e conflitos internos da organização sindical naquele período são reconstruídos. Esta análise permite cobrir as lacunas de uma das organizações sindicais menos estudadas na historiografia e sociologia espanholas. Também permite identificar os fatores que historicamente favoreceram a hegemonia dos sindicatos majoritários em nível estadual. Por fim, permite compreender como as representações da autonomia sindical e do intercâmbio político desempenham um papel importante na formação da estratégia sindical em diferentes níveis.
\end{abstract}

Keywords: União de Sindicatos. Autonomia Sindical. Transição Espanhola. Intercâmbio Político.

\section{Introducción}

El estudio sobre el movimiento obrero en la Transición española ha tendido a centrarse en el papel de las centrales que terminaron hegemonizando el campo sindical, las Comisiones Obreras (CCOO) y la Unión General de Trabajadores (UGT). No cabe duda de que dichas organizaciones, y sus partidos políticos afines, el Partido Comunista de 
España (PCE) y el Partido Socialista Obrero Español (PSOE), fueron actores clave de dicho periodo; sin embargo, otras fuerzas sindicales y políticas, que -salvo honradas excepciones- han sido ignoradas por la historiografía oficial hasta hace relativamente poco tiempo, también jugaron un papel destacado. Este es el caso de la Unión Sindical Obrera (USO), que en 1978, la época de expansión del movimiento obrero en España, afirmaba tener 550.000 afiliados (OLIET PALÁ, 2000), y de cuya trayectoria existen escasas publicaciones.

Este artículo pretende responder a ese vacío historiográfico. Se propone reconstruir y analizar la evolución de la Unión Sindical Obrera en la provincia de Cádiz durante los primeros años de Transición a la democracia (1976-1981). Se parte de la premisa que la trayectoria de este sindicato en la provincia de Cádiz refleja las tensiones internas, los marcos de referencia y las dinámicas organizativas, la organización sindical en su conjunto. Así, se describe el proceso de constitución de la USO, su implantación en el tejido laboral gaditano, la expulsión de toda la estructura territorial de Cádiz y, finalmente, la reconstrucción de un sindicalismo autónomo agrupado en torno a la Confederación Libre y Autónoma de Trabajadores (CLAT), que tendría pocos años de vida.

Este trabajo se basa, principalmente, en testimonios orales de los protagonistas de aquella época. La técnica principal de recogida de información ha sido la entrevista semiestructurada, que se ha llevado a cabo a través de un muestreo intencional. En concreto, se han analizado 25 entrevistas. Una parte (15) de estas entrevistas fueron realizadas en 2008 como parte de un proyecto de investigación que fue finalizado sobre la lucha sindical en el astillero de Puerto Real': 14 a sindicalistas del astillero de Puerto Real (siete de ellos pertenecientes a la USO en el periodo de Transición a la democracia) y a un abogado laboralista que trabajó durante más de veinte años para el Colectivo Autónomo de Trabajadores (CAT), procedente de la USO. Las otras 10 entrevistas fueron realizadas en 2016 a antiguos sindicalistas de la USO y al Sindicato Autónomo de la Vid (SAVID) del Marco de Jerez. A través de esta técnica dialógica se solicitó a los sujetos que narraran en

\footnotetext{
1 Proyecto "Mujeres en el movimiento obrero en el Marco de Jerez, 1960-2017" (ref. 2017-047/P01-BRM$\mathrm{EBF}$ ), financiado por la agrupación de electores Ganemos Jerez.

Proyecto "Del antifranquismo a la marginalidad: disidencias políticas y culturales en la transición española a la democracia" (HAR2016-79134-R), del Programa Retos de la Sociedad. del Ministerio de Economía, Industria y Competitividad
} 
sus propios términos sus experiencias biográficas, laborales y sindicales, haciendo énfasis en el periodo de construcción de la USO y las luchas laborales. Las entrevistas, además, permitieron preguntar por sus motivaciones ideológicas y religiosas con el objeto de acceder a sus marcos de referencia (ROCA; FLORIDO, 2015; SNOW; BENFORD, 1988). Las fuentes orales han sido complementadas con el análisis de documentos (como folletos, actas de reuniones, fotografías y noticias de prensa de dicho periodo) a los que se ha tenido acceso por medio de los sujetos entrevistados.

El artículo comienza contextualizando los orígenes de la USO en España. A continuación describe el papel de los círculos cristianos en la reconstrucción del movimiento obrero gaditano en el tardofranquismo y en el periodo de Transición, relacionándolo con el marco político y económico más general. Posteriormente, se analiza el desarrollo de la USO en dos sectores clave de la economía gaditana: la construcción naval en la zona de la Bahía de Cádiz, y el sector bodeguero en el Marco de Jerez. Se han elegido ambos sectores por ser aquellos en los que esta central sindical adquirió mayor protagonismo, logrando superar incluso a las CCOO y la UGT en determinados periodos. Por último, este trabajo describe y analiza el proceso de declive de la USO a finales de la década de 1970 y la creación de nuevas organizaciones sindicales autónomas.

\section{Orígenes de la USO}

Durante la dictadura, un importante sector de la Iglesia católica se va separando de la línea nacional-católica que afecta al régimen de Franco, y va dando la cobertura a la reestructuración del movimiento obrero y las luchas laborales. En 1946 se fundó la Hermandad Obrera de Acción Católica (HOAC), por dirección de la jerarquía eclesiástica, con el objeto de dar respuesta a la creciente desafección de los trabajadores al sistema político y sus problemas socio-económicos. Pronto se extendió por todo el territorio nacional y se instaló en la provincia de Cádiz. En 1951, con los mismos objetivos, se creó la Juventud Obrera Católica (JOC), especializada en los jóvenes trabajadores y su problemática, y que se acercaría a la HOAC. 
Los cambios políticos que se producen a nivel estatal, a finales de la década de 1950, propiciaron el desarrollo del sindicalismo en la clandestinidad, además de cambios en los regímenes industriales. El Plan de Estabilización Económica, que fue aprobado por el Gobierno en 1959, con el objeto de liberalizar la economía y de favorecer el crecimiento económico, supuso una mayor apertura del régimen. La Ley de Convenios, que fue aprobada un año antes, en 1958, ofrecía nuevos -aunque estrechos- canales de representación de los trabajadores y de reivindicación laboral a través del Sindicato Vertical. Ambas políticas crearon un clima favorable para la reconstrucción del movimiento obrero, abriéndose una etapa de incremento progresivo de la movilización obrera que duraría hasta la muerte del dictador (SÁNCHEZ RECIO, 2002).

En este contexto, a finales de los cincuenta, aparecen en Asturias los primeros grupos de lo que pronto sería la Unión Sindical Obrera (USO), formados por sacerdotes y jóvenes que eran vinculados a la HOAC y a la JOC (SERVICIO CENTRAL DE DOCUMENTACIÓN, 1975). Eugenio Royo, que entre 1957 y 1960 había sido el primer presidente nacional de la JOC, logró aglutinarlos en la clandestinidad y, bajo su liderazgo, se redactó la Carta Fundacional. Sobre esta base, en 1961, se constituyó en Madrid la USO como organización sindical de nuevo cuño de inspiración social-cristiana, siguiendo el ejemplo de la CGIL (Confederazione Generale Italiana del Lavoro) italiana, que fue fundada en 1948, y la CFDT (Confédération Française Démocratique du Travail) francesa, que había sido reagrupada en 1944-1945 tras la liberación de Francia y que mantuvo la línea cristiana hasta mediados de la década de 1960 , en la que se impuso el sector favorable a la "desconfesionalización". En 1965 constituyó un Comité coordinador, que ratificó en su declaración de principios los enunciados de la Carta Fundacional que fue aprobada en 1961, que era articulada en torno a las nociones de autogestión y democracia socialista (IGLESIAS, 1976).

En sus estatutos iniciales, la USO se identificaba con el socialismo autogestionario: "organizar la lucha y la concienciación de todos los trabajadores para transformar la empresa capitalista, que antepone el beneficio a los intereses colectivos, hacia una organización del trabajo más humana, creativa y de autogestión"; aunque la adscripción 
Durante la década de los sesenta, en el interior de la Iglesia Católica, continuaron produciéndose transformaciones. En 1966 hubo una crisis en el seno de Acción Católica, que reflejó la creciente ruptura en las organizaciones seglares con el régimen franquista. Esta crisis fue sin duda un primer efecto del Concilio Vaticano II, que ha sido celebrado entre 1962 y 1965, que reflejó un cambio de orientación en toda la Iglesia, acercando el evangelio a los problemas de pobreza y desigualdad, y reforzando en España el sector eclesiástico que se oponía a la dictadura.

La USO, al igual que Comisiones Obreras, abogó por la estrategia de infiltrarse en el Sindicato Vertical franquista, para aprovechar los recursos y el espacio político (FOWERAKER, 1990). Hasta 1967 la USO colaboró en la creación de Comisiones Obreras para organizar la lucha dentro del régimen franquista, pero en dicha fecha, debido a la creciente influencia que fue ejercida por el PCE sobre las Comisiones Obreras, la USO se separó, definitivamente, de dicha organización. El crecimiento de la USO no fue tan rápido como el de las Comisiones Obreras. En 1971 contaba con un Consejo Peninsular, máximo órgano de dirección, y con un Comité Exterior, con sede en París. No obstante, aunque ya existían núcleos activos en Asturias, Cataluña, Madrid, el País Vasco, Navarra y Murcia, todavía era poco conocida (SERVICIO CENTRAL DE DOCUMENTACIÓN, 1975, p. 3).

Ese mismo año se produjo la salida de los sectores más radicales, minoritarios, que propugnaban la conversión en un partido de vanguardia ${ }^{2}$. La escisión hizo desaparecer la USO de Asturias y en Madrid quedó seriamente diezmada al igual que en la costa mediterránea. Los efectos sobre el País Vasco fueron más matizados, limitándose a Vizcaya (SERVICIO CENTRAL DE DOCUMENTACIÓN, 1975, p. 3).

Al contrario de lo sucedido con la Acción Sindical de Trabajadores (AST), que en un proceso parecido se había transformado en partido en 1970, adoptando el nombre de Organización Revolucionaria de Trabajadores (ORT) (PÉREZ SERRANO, 2013), la USO sobrevivió como sindicato y poco a poco logró recuperarse. Su mayor triunfo, en los años

\footnotetext{
2 Liderados por el comité de Asturias, los radicales celebran un congreso disidente en Valladolid, constituyéndose en partido, pero pronto desaparecen.
} 
de la dictadura, se produjo en 1974 cuando uno de sus miembros fue admitido en la Organización Internacional del Trabajo (OIT), donde estaban las Comisiones Obreras, la UGT y el sindicato Solidaridad de los Trabajadores Vascos (ELA-STV) (SERVICIO CENTRAL DE DOCUMENTACIÓN, 1975).

En la historia de la USO, al menos hasta su legalización en abril de $1977^{3}$, podemos distinguir tres fases. La primera, que abarca toda la década de los sesenta, estará marcada por el liderazgo de Eugenio Royo y la vigencia de la Carta Fundacional, que define la organización como libre y

abierta a todos los trabajadores que, en el respeto mutuo de sus convicciones filosóficas, políticas y religiosas, buscan el pleno desarrollo de la persona en la perspectiva de una estructuración democrática de la Sociedad basada en el Trabajo, la Paz y la Justicia (SERVICIO CENTRAL DE DOCUMENTACIÓN, 1975, p. 3).

La segunda etapa se inicia a comienzos de los setenta y llegará prácticamente hasta su legalización. Esta fase estará muy influida por la experiencia del Mayo francés, del que la USO hace una lectura radical que desemboca en las posiciones del sindicalismo revolucionario. En 1973 se produce el relevo de Eugenio Royo en la secretaría general, que pasa a Manuel Zaguirre. La USO, orientada desde 1974 por teóricos como Manuel Reyes Mate, intentó desarrollar una teoría propia que, superando la dicotomía partido-sindicato, le permitiera "ser el instrumento para la conquista del poder por la clase obrera" (SERVICIO CENTRAL DE DOCUMENTACIÓN, 1975, p. 8). Así, en 1970, la USO se declara organización revolucionaria y formula su estrategia de masas en abierta contraposición con los partidos, a los que acusa de no responder a los intereses y a las aspiraciones de los trabajadores. Rechaza, por ello, la idea de un partido de vanguardia y promueve las asambleas y los comités obreros como forma de democracia directa en la perspectiva de una futura sociedad autogestionaria (REYES MATE, 1977).

A partir de 1977, poco a poco irá adoptando posiciones más moderadas que la acercan a las CCOO y la UGT, aunque la retórica de la USO continuó reclamando hasta 1980 el poder para los consejos obreros. De hecho, tras su legalización, celebró su I

\footnotetext{
${ }^{3}$ El 29 de abril de 1977 fueron legalizadas CCOO, UGT, USO, ELA-STV y Solidaridad de Obreros de Cataluña (SOC) (ARRIBA, 1977).
} 
Fruto de estas contradicciones y ante el nuevo escenario político, el sector de inspiración socialista de la USO, partidario de la unidad sindical, se integró a la UGT en un Congreso Extraordinario que fue celebrado el 18 de diciembre de 1977 (PÉREZ SERRANO, 2010). Los enfrentamientos internos en el sector de la USO, que no aceptó la integración, provocaron nuevas escisiones protagonizadas, en este caso, por los sectores radicales. La más importante fue la de la Corriente Socialista Autogestionaria, liderada por José Corell, articulada en torno al Centro de Debate y Estudios Sindicales Autonomía Obrera (CEDES), que ingresó a las CCOO, en marzo de $1980^{4}$ (EL PAÍS, 1980). En Galicia y Asturias, los radicales constituyeron nuevos sindicatos. En Madrid, el Partido Sindicalista anunció que sus militantes, liderados por Francisco Zugasti, secretario de la Federación Castellana, abandonarían la USO para integrarse en la CNT-Renovada (CGT desde 1989). En Andalucía, donde los radicales eran mayoritarios, fue, especialmente, dura. Ambas fracturas debilitaron, notablemente, al sindicato y contribuyeron su moderación, ya que, después de 1980, la USO abandonó la idea autogestionaria. El núcleo dirigente, con su secretario general Manuel Zaguirre a la cabeza, logró resistir el envite, consolidando la USO como la tercera fuerza en las sucesivas elecciones sindicales que fueron celebradas desde 1978.

\section{Cristianos en el movimiento obrero y los orígenes de la USO en Cádiz}

El movimiento de la HOAC y la JOC, en Cádiz, tiene como núcleo inicial la parroquia de San Francisco Javier de la Barriada de la Paz, de la capital gaditana, con el párroco Miguel Mougán a la cabeza. Desde allí, se llevó un intenso trabajo de concienciación y denuncia. Estuvo expuesta a control policial y detenciones en comisaría, que afectaron, especialmente, a los líderes de la HOAC de aquel momento, como a Antonio Aragón, a Paco Medina, a Manolo Ocaña, a Hipo, a Añino, o al médico portuense Jaime San Narciso. A pesar de ello, el apoyo del obispo Añoveros a los hoacistas logró contener la represión en numerosas ocasiones (MILLÁN CHIVITE, 2005).

\footnotetext{
${ }^{4}$ No obstante, en 1985 un sector abandonó CCOO y se pasó a la UGT (EL PAÍS, 1985).
} 
La HOAC y la JOC contribuyeron al movimiento obrero gaditano en una doble dirección. Por un lado, propiciaron un armazón ideológico y doctrinal para respaldar a los curas progresistas, favoreciendo que algunos de ellos llegaran a formar parte del movimiento de curas obreros. Por otro lado, estas asociaciones seglares ofrecieron lugares seguros de reunión, debate y almacenamiento de propaganda sindical en la clandestinidad, estimularon la formación de cuadros sindicales, denunciaron las injusticias laborales de acuerdo con la Doctrina Social de la Iglesia, e incluso Ilegaron a apoyar, directamente, las reivindicaciones y las luchas laborales concretas (TORRES BARRANCO, 2015).

Poco a poco, desde estos espacios cristianos obreros se impulsó, por un lado, el movimiento de curas obreros, que desempeñaron un papel destacado en las luchas sindicales gaditanas, con sacerdotes como Ramón Gaitero, José Vitini o José Fajardo, entre otros; $y$, por otro lado, fue adquiriendo forma la idea de promover un sindicalismo de inspiración cristiana y socialista. A los pocos meses de su constitución en Madrid se forman grupos de la USO en Cádiz, y desde ahí, se va extendiendo a numerosos sectores laborales de la provincia. En la provincia de Cádiz, la corriente autogestionaria tuvo una fuerte presencia. Sebastián González, hoacista y dirigente de la USO en Jerez por aquel entonces, por ejemplo, recuerda cómo llegaron publicaciones de la antigua Yugoslavia que se distribuyeron entre sus círculos:

Los sindicatos nos planteamos, especialmente la USO, se planteó... Nosotros, desde Yugoslavia, recibimos una ayuda, unos materiales, libros como: ¿Qué es la autonomía?, ¿Qué es la autogestión?, sobre los concejos de barrios, o sea, toda una serie de cosas que estaban bien para los italianos que llevaban tiempo trabajando en libertad y para los franceses que también tenían mucho interés (GONZÁLEZ, 2016, entrevista oral).

La estrategia de la USO, que era respaldada por la HOAC y la JOC, incluyó también la formación de cuadros, consiguiendo capacitar a los principales líderes del movimiento obrero gaditano de la época, como a Esteban Caamaño (del sector bodeguero portuense), a Sebastián González (del sector bodeguero jerezano), a José Luis Rodríguez Añino (la construcción naval de Cádiz), a Manuel Cañas Sánchez (Bazán S.A. de San Fernando) y a Isidro Gálvez (MELLADO MORALES, 2004). 
La estrategia de infiltración, en el Sindicato Vertical, facilitó la reactivación de la reivindicación obrera en la provincia, permitiendo participar en la negociación de convenios y compaginar la lucha legal y extralegal. Además, permitió que la USO y la CCOO adquirieran una experiencia y nivel de implantación mucho mayor que las organizaciones sindicales históricas, Unión General de Trabajadores (UGT) y Confederación Nacional del Trabajo (CNT), que habían rechazado participar en las estructuras sindicales del régimen franquista. Según los testimonios de los informantes, en ese contexto la USO no tenía afiliados, sino que formaron una red integrada por número reducido de cuadros que, posteriormente, se presentaban a las elecciones de los jurados de empresa. Coloquialmente, se denominaba "verticalistas" a los falangistas y a los adeptos al régimen que estaban en el sindicato Vertical, y "democráticos" a los que estaban infiltrados desde las organizaciones de izquierda. Los militantes de estas redes clandestinas llevaban también una intensa labor de propaganda, tanto sindical como política.

En dicha época, los líderes de las organizaciones sindicales mantenían reuniones clandestinas en playas de El Puerto (como La Puntilla o Valdelagrana), iglesias o bares. La propaganda la escondían en parroquias o en domicilios de personas no fichadas por la policía. El médico portuense, Jaime San Narcisco, compró un "cuatro latas" (Renault 4) a la organización, que fue utilizado para la distribución de propaganda y para viajar por todo el estado a reuniones de coordinación de la USO. De este modo, y a pesar de la represión a los dirigentes (en forma de multas, detenciones e interrogatorios y tortura), en la segunda mitad de la década de 1970, una vez que fueron legalizadas las organizaciones sindicales, la USO se convertiría en la principal fuerza sindical en el sector del metal gaditano (principalmente, en los astilleros de Cádiz y Puerto Real, Construcciones Aeronáuticas S.A. y Bazán S.A.), con alrededor de 12.000 afiliados, y en el sector bodeguero del Marco de Jerez. La provincia de Cádiz se convirtió en uno de los bastiones de la USO (PIÑEIRO BLANCA, 2009), con 14 federaciones de ramo, como Administración Pública, Sanidad, Artes Gráficas, Comercio, o Banca. Buena parte de su militancia estuvo influida por las ideas socialistas autogestionarias y católicas. 


\section{La USO en el sector de la construcción naval gaditana}

Los tres astilleros gaditanos (de Cádiz, Puerto Real y San Fernando), pertenecientes los dos primeros a Astilleros Españoles S.A. y el tercero a Bazán, las tres empresas públicas, constituían la principal fuente de empleo de la Bahía de Cádiz. En su momento de máximo esplendor, empleaban directa o indirectamente -a través de empresas auxiliares- a alrededor de 40.000 trabajadores. Dichos enclaves fueron un terreno fértil para el desarrollo del sindicalismo, de ideologías opuestas al franquismo y de repertorios de acción colectiva que han sido caracterizados por su radicalidad (FLORIDO; ROCA; GUTIÉRREZ, 2013), que han sido reforzadas por unas culturas del trabajo particulares que arraigaron tanto en los trabajadores como en las comunidades en las que residían.

A pesar de la clandestinidad, la militancia de la USO y de la CCOO se presentaba, individualmente, a las elecciones del jurado de empresa desde la década de 1970 en los tres astilleros gaditanos. Actuaban así, dentro del estrecho margen que el "Sindicato Vertical" concedía, para la negociación colectiva y la representación de los trabajadores. Eso hizo que la USO y la CCOO tuvieran más militancia, experiencia y proyección que la UGT en aquellos momentos.

En el astillero de Puerto Real destaca el liderazgo de Pepe Zorrilla, a quien los sindicalistas que han sido entrevistados recuerdan como un hombre con una visión extraordinaria. Zorrilla desempeñó el cargo de secretario del jurado de la empresa en la década de 1970, y participó, activamente, en las negociaciones y en las luchas por los convenios colectivos, defendiendo subidas salariales lineales en lugar de porcentuales con el objeto de ir reduciendo las desigualdades entre las diferentes categorías.

En 1977, con los sindicatos ya legalizados, ante los signos evidente de una reconversión del sector de la construcción naval a nivel estatal, los militantes de la USO, de la CNT, de la CCOO y de la UGT organizan encierros y movilizaciones en defensa del empleo, buscando, en todo momento, el apoyo de la comunidad (PÉREZ DE GUZMÁN, 2012). A principios de 1977 comienzan las movilizaciones contra la reconversión. La primera acción fue un encierro en Parroquia de la Divina Pastora de la ciudad de San 
destacado como militante de la CNT:

\begin{abstract}
Allí, planifico una propuesta de encierro. Eso es en el año 77. Que lo boicotea el Barroso. Nos quedamos primero 16 en el comedor. Yo busco los tableros, mantas de los barcos, empezamos a organizar aquello, incluso contra a la gente de mi propio sindicato, de la USO. Que no era conveniente, por aquello de la unidad... El mismo discurso de siempre. Se monta un encierro, 16 o 17 días. Montamos una biblioteca. Debates todas las noches. Al otro día éramos 30, y 40, y 100, y 300, y 400. Bueno, aquello fue ya una cosa impresionante. Con huelgas de hambre. Nos íbamos a la carretera todos los días. Nos encadenamos (GÓMEZ, 2008, entrevista oral).
\end{abstract}

Paralelamente de ese proceso, realizan una intensa campaña de información y movilización en la sociedad civil de la Bahía de Cádiz, que culmina en agosto de ese año en la que los informantes consideran la primera manifestación masiva por el problema de la construcción naval en Cádiz, en la que participaron 10.000 personas. Durante esos meses van compaginando movilizaciones en las ciudades de la Bahía con encierros en el interior de la factoría. Las aportaciones de Antonio Carbú, trabajador afiliado a la USO y letrista de Carnaval, fueron significativas para la elaboración de pancartas.

Ante la situación de crisis y los problemas del sector, los sindicatos junto a los trabajadores que han sido elegidos en asamblea y los representantes de la empresa auxiliar constituyeron la Coordinadora de Trabajadores de AESA Puerto Real, que se encargaría de coordinar y representar a los trabajadores ante la empresa y las autoridades públicas. En el astillero de Cádiz se constituye una Coordinadora igual. Las protestas se radicalizan, aunque la Coordinadora se disuelve por falta de unidad entre las organizaciones sindicales. Finalmente, en julio de 1978 se firman, a nivel estatal, los "Pactos de la Castellana", por los cuales CCOO, USO, UGT y ELA-STV aceptan un sistema de regulaciones temporales rotativas y bajadas salariales a cambio de conservar todos los puestos de trabajo. Esos acuerdos permitieron, posteriormente, llevar a cabo la integración del personal de la industria auxiliar en la empresa matriz, Astilleros Españoles 
S.A., algo en lo que los militantes de la USO trabajaron, activamente, por la vía jurídica y por la movilización en Cádiz.

En el año 1978 también se celebran las primeras elecciones sindicales, en las que la USO se convierte en la fuerza mayoritaria entre el personal de plantilla y la CCOO, entre el personal de las empresas auxiliares gaditanas. La UGT obtiene algunos delegados, y la CSUT y la CNT se quedan fuera de los Comités de Empresa de los astilleros.

En 1977 se había producido la primera gran escisión en el seno de la USO a nivel estatal. Un sector importante decidió integrarse en la UGT. Algunos de los que se pasaron a la UGT eran militantes de los astilleros gaditanos. En 1979, con la expulsión de un importante contingente de militancia y su posterior integración en la CCOO, las secciones sindicales de la USO pierden parte de su afiliación. Ante esta situación y teniendo en cuenta el contexto de reconversión en el que se encontraban, deciden proseguir su actividad sindical con el nombre de Autonomía Sindical:

Nosotros hacemos Autonomía Sindical por el debate que se hace en la USO de que un líder se va a Comisiones como que otro se va a la UGT. Y los que no estamos ni por Comisiones ni por la UGT, bueno, pero optamos en Puerto Real, porque había un cuadro muy importante de personas, y muy significativas, y cualificadas, para llevar esto para adelante. $Y$ claro, con unas reconversiones que se venían encima nosotros, no podíamos quitarnos de en medio. Creamos Autonomía Sindical (CRUZ, 2008, entrevista oral).

Con esas siglas se presentan a las elecciones sindicales en los astilleros gaditanos, pero a los pocos meses, al tener afiliados en otros astilleros públicos y privados de otras partes de España, constituyen el Colectivo Autónomo de Trabajadores (CAT), que tendría representación en el comité de empresa y desempeñaría un papel destacado en las luchas contra la reconversión industrial en la década de 1980 (FLORIDO; GUTIÉRREZ; ROCA, 2009).

\section{Implantación en el sector bodeguero del Marco de Jerez}

La principal actividad económica del Marco de Jerez aparece asociada a la producción de vino. Los vinos generosos del Marco de Jerez están amparados por la 
denominación de origen "Jerez-Xérès-Sherry" y "Manzanilla Sanlúcar de Barrameda". Además, se produce el "Vinagre de Jerez" y el brandy de Jerez (SOLER, 2006). El sector bodeguero era, en la década de 1970, una industria formada, principalmente, por grandes empresas propiedad de familias endogámicas (que, además, eran las propietarias de las grandes extensiones de viñas cultivadas en el Marco de Jerez); aunque también coexistían con cientos de pequeñas y medianas bodegas de carácter familiar.

El sector llegó a emplear a unos 8.000 trabajadores de manera directa (EL PAÍs, 1979), y a varios miles de las empresas asociadas o auxiliares, como Artes Gráficas, Jerez Industrial, Cartonajes Tempul, la fábrica de botellas, tonelería, comercio, etc. La dependencia económica y laboral de las ciudades del Marco, respecto de la industria bodeguera, era absoluta. Además, estaba asociado al sector de la Viña, que podía emplear a unos 40.000 trabajadores en los periodos de máxima actividad en el conjunto del Marco, en este sector, perteneciente al Campo y no a la industria y presentaba características propias, ya que las propiedades agrarias en general pertenecían a las mismas familias latifundistas que eran poseedoras de las enormes fincas, como Las Lomas en Jerez o La Almoraima, uno de los mayores latifundios de Europa5.

La USO, en la década de 1970, fue mayoritaria en el sector bodeguero, tanto en bodegas grandes como pequeñas, también en las empresas auxiliares. En el campo, sin embargo, la CCOO obtuvo la hegemonía. Los inicios de la USO, en las bodegas del Marco de Jerez, vienen determinados por la pertenencia de muchos de sus militantes a las organizaciones católicas. Procedentes del sector de la vid, destacaron a los líderes regionales y provinciales como a Esteban Caamaño, arrumbador de Terry, a Sebastián González, trabajador de Domecq, o a Pepe Gaitero, empleado de Palomino y Vergara. Todos ellos estuvieron vinculados a los movimientos católicos de la JOC y la HOAC, desde principios de 1960. El inicio de la actividad sindical se vincula con sectores de la lglesia con José María Cirarda, Obispo Auxiliar de Sevilla con residencia en Jerez, que funcionaba

\footnotetext{
${ }^{5}$ El convenio colectivo de las Viñas se negociaba aparte, pero influía en el desarrollo de la acción colectiva en la Vid, como pudo palparse en huelgas posteriores. Los viticultores paralizaron en muchas ocasiones la vendimia, a lo largo de las décadas de 1970 y 1980, en diferentes huelgas que tuvieron importante repercusión. Si bien es cierto que también existía un gran número de propietarios que se unían en las Cooperativas del Marco y vendían su producción a las grandes bodegas, dentro del Marco de Jerez, en cuya patronal poca voz tenían frente al poder de los grandes propietarios.
} 
Nosotros tenemos lo que todos hemos echado de menos y hemos llorado, es el tema de la formación. Nosotros elaboramos unos materiales para la Escuela de Formación de Delegados Sindicales, que era una preciosidad. Nosotros, además, lo adaptábamos, pero, ¡fíjatelos tú! Cogíamos los materiales, citábamos a la gente con mucho cuidado e íbamos a un convento en Cádiz, concretamente a las monjas que están el Pópulo, allí en Aníbal Barca (...) pasábamos, que, además, al pasar la iglesia, cogía la monja y abría el sagrario y sacaba el cáliz, y rezaban, y nosotros estábamos en el otro lado con un material sobre el capitalismo, discutiendo, debatiendo, enriqueciéndonos (GONZÁLEZ, 2016, entrevista).

Pepe Gaitero, otro de los sindicalistas bodegueros, explica cómo determinados sacerdotes desempeñaban una labor propagandística, educativa y de agitación entre la juventud. Impulsando, de este modo, las JOC:

También, había un libro que hablaba de la JOC, Juventud Obrera Cristiana, y eso me hizo tener ilusión y a través de un centro católico obrero que había en Jerez, en la Compañía de Jesús. Por cierto, me preocupé. Me enteré que había JOC en Sanlúcar. Un tal padre Julio que fuera que nos explicara. Y a la barriada de la Asunción vino ese cura (...) y habló también de la rebeldía de los jóvenes frente a la sociedad. Y todo estaba en el ámbito de los jóvenes y cómo tenían que modelar una sociedad que habían heredado y no era a su gusto y medida. Se implanta un poco la JOC a través de un hermano mayor mío [Ramón Gaitero]. A última hora yo era el que la busqué y él fue el que implantó la JOC aquí en Jerez. Es la primera organización apostólica obrera que se implanta, en últimos 50 y los medios (GAITERO, 2016, entrevista oral).

A pesar de la protección eclesiástica y de actuar dentro del paraguas del régimen, la represión afectó a numerosos líderes y militantes obreros. Sebastián González, líder de la USO, cuenta cómo durante la dictadura y su final, en los tiempos en que aún actuaban en la clandestinidad, lo detuvieron varias veces y era la USO la que tenía que pagar las multas de 15.000 pesetas que imponían a cada detenido. Explica que los compañeros de la Federación de la Banca (donde la USO también era mayoritaria), a través de la Caja de Ahorros de Jerez, apoyaban para proveer fondos para estos casos: 
Yo me acuerdo que, con Juan Pérez, de Comisiones Obreras, y yo, que organizamos el uno de mayo, en Jerez, en la Parroquia Perpetuo Socorro (...) en el 1964-66, y le mandó un telegrama al Gobernador Civil: Juan Pérez y Sebastián González no ofrecen garantía de respeto democrático a esta autoridad. Luego, por lo tanto, se ven en el derecho de decirle que no te autorizan la manifestación. No bastante, nos fuimos a la tabacalera, cantamos y nos echaron 15.000 pesetas de multa, a todo el que cogieron. A mí me cogieron fácilmente, porque yo era cojo y no corría (GONZÁLEZ, 2016, entrevista oral).

La estrategia de infiltración, en el Sindicato Vertical, llevó a los militantes clandestinos de la USO y de la CCOO a los Jurados de Empresa, de empresas como Domecq, González Byass, Osborne, Terry, Díez Mérito, Williams, Sandeman, o Valdespino, entre otras. De este modo, fueron tomando posiciones y fueron creando estructuras de representación en sus centros de trabajo, antes de las primeras elecciones sindicales.

Sin embargo, la enorme disparidad de condiciones laborales entre bodegas, especialmente, entre grandes y pequeñas, fue una enorme dificultad para organizar a los trabajadores y luchar por un convenio para el sector. A esta dificultad, había que añadirle las prácticas paternalistas de los empresarios y la falta de concienciación de los trabajadores. Respecto a las grandes empresas, la concentración de altos números de trabajadores facilitó la acción colectiva, pero también de una serie de beneficios como un economato, ayudas a estudios de hijos en el colegio de los Hermanos de la Salle, las ayudas a la jubilación en el Montepío de San Ginés, o la construcción de barrios enteros para los obreros, con participación del Ministerio de Vivienda (como San Ginés de la Jara, Barriada Domecq, La Asunción, La Vid, Las Viñas, o Eduardo Delage, entre otros). Respecto al paternalismo que fue desarrollado en las bodegas y su influencia en la mentalidad de los obreros de la Vid, los sindicalistas que fueron entrevistados comparten visiones similares:

Las luchas en la vid eran muy difíciles porque el trabajador de Jerez ha mirado mucho al señorito. Lo tenía muy arraigado y se ha coscado muy poco. Ha hecho estragos. Aquí, el señorito, nada de señorito, el patrón o el dueño de la empresa, nada de señorito. Afortunadamente, la palabra amo ha desaparecido hace mucho tiempo, en el XIX. Algunos se creían que lo iban a enterrar con el amo. El pueblo de Jerez es un pueblo servilista. Es historia, pero de ahí venimos (PÉREZ GIL, 2016, entrevista oral). 
La concentración geográfica en lugares de trabajo y barrios, los fuertes vínculos laborales y emocionales con las bodegas, que se plasmaron en culturas de trabajo particulares, sirvieron de catalizador para la organización sindical. En este contexto, ante la falta de concienciación de los trabajadores, los sindicalistas optaron por promover la formación. El siguiente informante explica que uno de los problemas del sindicalismo contemporáneo es, precisamente, haber abandonado esa dimensión:

En el sindicalismo se ha dejado la formación y el estilo de organizaciones nuestras sin formación, no es nada. Es el pilar básico de la organización, la formación. (...) porque ya organizaciones obreras no, son tingladillos. Luego, la formación ha dado el fin al sindicalismo. Una vez que los sindicatos dejaron la formación al lado, ya ni se creó conciencia, la militancia no existe. Es como un seguro. Yo pago la cuota y ya está (PÉREZ GIL, 2016, entrevista oral).

La década de 1970 fue un periodo de expansión y crecimiento del sector bodeguero del Marco. Se incrementaron las ventas y el volumen de negocio. De hecho, la oferta en ocasiones no lograba superar a la demanda, sobre todo para la exportación que suponía el 90\% de la producción (MEDINA GARCÍA DE POLAVIEJA, 2014). En este contexto, la actividad sindical y la huelguística se intensificaron notablemente.

En 1974, los podadores de viña protagonizaron una dura huelga, que afectó a unos 40.000 trabajadores. La solución de la patronal fue la contratación de 600 trabajadores foráneos para sustituir a los huelguistas. En las bodegas, la negociación de convenios y la actividad sindical fueron constantes, a pesar de las dificultades.

En las primeras elecciones sindicales en democracia, en 1978, ya había problemas internos en la USO, aunque eso no impidió que ganara por mayoría ${ }^{6}$. La USO, en aquel momento, se convirtió en la primera fuerza sindical de las bodegas y, por extensión, de todo el Marco de Jerez.

\footnotetext{
${ }^{6}$ Sin embargo, en 1978, las tensiones con la ejecutiva de la USO son notorias. La Federación de la Vid, al igual que el resto de las federaciones de la provincia de Cádiz, percibirá la línea de Manuel Zaguirre y los rumores sobre el acercamiento con la UCD, como una renuncia a la autonomía sindical, y el conflicto interno se saldará con la expulsión de toda la provincia de Cádiz del sindicato (como se explica en el apartado siguiente).
} 
En los años siguientes años hubo varios conflictos, pero el más destacable se produjo en abril de 1979. En esa fecha, USO, CCOO y UGT hicieron un Ilamamiento a la unidad sindical, por la negociación del convenio. Después de 30 días de huelga, más de 100 bodegas fueron paralizadas y 8000 trabajadores la secundaron. La huelga se llevó a cabo en todo el sector, implicando a todas las bodegas de Jerez, Sanlúcar, El Puerto de Santa María y Chiclana. Los Comités de Empresa se encerraron en el edificio de la Administración Institucional de Servicios Socio-profesionales (AISS), en Jerez ${ }^{7}$, sin aceptar el laudo de vigencia del convenio anterior, donde se les incrementaba el salario base un 14\%, además de los complementos y de la formación. En este caso, los trabajadores concentrados en la Plaza del Arenal y desde el edificio de la AISS cantaron la internacional con el puño en alto al paso de una procesión, aunque el encierro terminó ese mismo día con la intervención de las fuerzas del orden público. Durante esta larga huelga se contó con las aportaciones de una caja de resistencia que se abrió en la Caja de Ahorros de Jerez, "Solidaridad con los trabajadores de la Vid", para poder soportar los gastos de la prolongada huelga.

En los años, inmediatamente, posteriores en el panorama laboral de la Vid se dan numerosos conflictos, manifestaciones, encierros y demás medidas de acción colectiva en el sector, debido a los cierres de empresas asociadas -como la embotelladora de El Puerto, en 1981, y más tarde, Jerez- o despidos colectivos como en Domecq, llegando al cierre patronal en 1982 o los expedientes de regulación de empleo de Terry, de más de 100 trabajadores que llevaron a movilizaciones de trabajadores, en defensa de los puestos de trabajo y que serían el precedente del desmantelamiento posterior de la industria bodeguera, debido a la desindustrialización de la provincia (EL PAís, 1982).

En 1983, se pone en marcha el Plan Global del Marco de Jerez para el redimensionamiento y la adecuación de una estructura que, en la década anterior, se había ampliado por el crecimiento de la demanda, unido esto a la pérdida de ayudas financieras y fiscales del sector. Pero, el inicio de la desindustrialización del sector vitivinícola había comenzado antes, al igual que en el sector naval en la provincia de Cádiz

\footnotetext{
7 Edificio que es conocido, en la actualidad, como el "edificio de los sindicatos", pues fue cedido a estas organizaciones como parte del Patrimonio Sindical Acumulado.
} 
El rápido deterioro de la empresa privada, frente a la pública, provoca que en las principales bodegas con mayor volumen de negocio y empleo desarrollen políticas de regulación con la consecuente pérdida de empleos en el sector, desencadenándose con ello una pérdida de vida económica y laboral paralela en las industrias asociadas. Según estimaciones en base a datos de FEDEJEREZ (Federación de Bodegas del Marco de Jerez), la pérdida de empleos directos fijos, entre 1980 y 1985, cuando el sector ya había mermado en trabajadores pasó de 4.430 puestos de trabajo a 3.765, llegando cinco años más tarde a 1.500 (SOLER, 2006). Sin contar al sector de la Viña que se vio igualmente reducido, debido a las necesidades de adecuación a los dictados en materia agrícola y de superficie plantada de la entonces Comunidad Económica Europea. En este contexto de decadencia y rápidas transformaciones económicas, la tradición sindical que fue impulsada por la USO gaditana siguió manifestándose, aunque bajo otras siglas, principalmente el SAVID, aunque también en una parte de la militancia de las CCOO y la CNT.

\section{Expulsiones, escisiones e implantación de sindicatos autónomos}

Desde 1970, la USO había experimentado, a nivel estatal, tensiones internas, algunas de las cuales dieron lugar a escisiones, pero es a finales de la década cuando los conflictos internos se hacen más patentes. Con la Transición a la democracia, a partir de 1976, se van aprobando una serie de políticas públicas que crean un nuevo marco regulador de las relaciones laborales. Este marco consagra un sistema sindical pluralista, en el que diferentes organizaciones sindicales pueden coexistir en un territorio o empresa, y cuya representatividad se mide, principalmente, mediante los resultados en elecciones sindicales (GARCÍA CALAVIA, 2012). Se genera así con clima de competición inter-sindical, que va a influir, decisivamente, en las prácticas y en las estrategias de las organizaciones obreras. 
En este contexto, dos de los pilares de la identidad de la USO, la idea de unidad y de autonomía, fueron interpretados de diferentes formas y fueron utilizados en los debates internos sobre la estrategia sindical (ALMENDROS MORCILLO, 1978). En relación a la unidad, la Carta Fundacional de la USO explicitaba que el sindicato estaba destinado a desaparecer en una Gran Central Sindical Democrática de Trabajadores. La idea de unidad también se manifestó en la participación en diferentes estructuras sindicales unitarias que fueron creadas para favorecer la articulación del sindicalismo de clase, desde las Comisiones Obreras originarias hasta la Coordinadora de Organizaciones Sindicales (COS) de 1976. Aunque la COS tuvo poco recorrido, y en 1967 la USO rompió con las Comisiones Obreras, en varias ocasiones, sectores de la militancia y de la dirección del sindicato apelaron, al principio de unidad, para defender integraciones de la USO, bien en las CCOO, bien en la UGT. En concreto, en 1977, un importante sector del sindicato abandona la USO para integrarse a la UGT. En octubre de 1977, la USO celebró un congreso extraordinario que reafirmó su independencia de la UGT y eligió como Secretario General a Manuel Zaguirre.

En 1978, con Manuel Zaguirre a la cabeza, los militantes trataron de reorganizar el sindicato, refundando su identidad y valores, lo que originó nuevas tensiones internas (MONTES PITA, 2009). Una de las decisiones más polémicas fue la de incorporar a representantes independientes, que fue aprobada en el VII Consejo Confederal de 1978. Si bien la afiliación de independientes dio un impulso a la afiliación sindical y suponía una balsa de oxígeno frente a la competencia de las CCOO y la UGT, una parte de las bases lo percibió como una derechización del sindicato, dado que muchos de los independientes provenían del Sindicato Vertical y pertenecían a partidos de derecha. Por ello, la USO se fue dividiendo en tres facciones: una más moderada que abogaba por la concertación, las relaciones con todas las fuerzas políticas democráticas y hacer un bloque con la UGT; otra que abogaba por integrarse a las CCOO; y otra, con fuerte componente socialista autogestionaria (algunos de ellos estaban relacionados con la editorial ZXY). A nivel estatal, en marzo de 1980, encabezado por José Corell, un sector del sindicato termina abandonando la USO enfrentado con la dirección y decide integrarse en las CCOO. 
El otro componente de la identidad de la USO, la autonomía, entendida, principalmente, como independencia respecto a partidos políticos y cualquier otra entidad externa al sindicato era, precisamente, el más atractivo para el sector que abogaba por el socialismo autogestionario y fue utilizado como principio de defensa ante los intentos de integrarse a otras fuerzas sindicales o de vincularse a partidos políticos. Las reuniones de la dirección del sindicato con líderes de la UGT o de partidos, como la $U C D$, que se filtraban a través de la prensa, generaron un clima de malestar interno que terminó estallando. En 1978, la ejecutiva decidió expulsar a toda la provincia de Cádiz, por este motivo.

José María Gaitero, sindicalista jerezano de la USO en aquel momento, interpreta que el principal motivo de expulsión fue la discrepancia en torno a la propuesta del Secretario General Manuel Zaguirre, de conectar al sindicato, con la UCD, con el objeto de lograr los apoyos políticos y poder competir en igualdad de condiciones con las CCOO y la UGT, que tenían el apoyo del PCE y del PSOE, respectivamente.

[Zaguirre proponía] Hagamos alianza con la democracia cristiana belga y la holandesa, que aquí, su partido posible de democracia cristiana sea la UCD. Hagamos nosotros esa alianza y así ya estamos todos [los sindicatos, la USO, las CCOO y la UGT] en igualdad de condiciones. Entonces, algunos de aquí de Cádiz, que le advertimos a este hombre. En Cádiz, siempre hemos defendido la autonomía sindical como arma estratégica y leal al movimiento obrero, de iglesia, de partidos, de todo poder extraño que no emane de la asamblea. Si tú eso lo vas a rescindir... Y entonces, le dijimos a Zaguirre que Cádiz se iba. Cádiz y Valencia eran la mayor afluencia de militantes de la USO, y, además, ideológicamente, muy desarrollados y con mucha implantación... y bueno, las cosas [se ríe] me entero con el tiempo, no me lo avisan y no me dicen nada, que me han dado de baja del sindicato (GAITERO, 2016, entrevista oral).

Joaquín Cruz, sindicalista de la USO y, posteriormente, del CAT en el astillero de Puerto Real, interpreta que los intentos de integrar la USO en otros sindicatos respondían a los intereses particulares de los liberados del sindicato, que sabían que podían ganar más dinero en otras fuerzas sindicales que tenían mayor respaldo político: 
Porque aquello era un petardeo constante. $Y$ a nivel propaganda y a nivel de funcionamiento aquello no había quien lo aguantara. Esa era la realidad. Entonces, la USO como organización, a nosotros nos estaba haciendo un flaco favor. Sobre todo los líderes de la USO, que optaban por esas cosas. Hubo un Congreso expresamente para... Porque la idea no era que se fueran unos cuantos, la idea era: 'Nos integramos todos en tal sitio'. Eran un poco las ponencias, las propuestas que había en aquel, entonces. $O$ sea, yo no puedo decir: 'Mira, me voy porque yo que sé. $O$ tengo un mejor camino o lo que sea. No. Aquello era...' Te vuelvo a decir lo mismo. Tenía mucho que ver con la trayectoria política: tema de liberados. Cuando un liberado en la USO no ganaba nada, un liberado en otro sindicato pues estaba bien. Yo creo que esas cosas influyen, en las cuestiones personales, no en cosas ideológicas (CRUZ, 2008, entrevista oral).

Sebastián González, otro de los dirigentes de la USO, en el Marco de Jerez, ofrece otra interpretación. Desde su punto de vista, lo que rompe a la USO es la mala situación financiera. Al perder los recursos del sindicato vertical para el desarrollo de la acción sindical, la USO está endeudada y las únicas opciones de salir adelante por parte del Secretario General, pasaban por integrarse en la UGT o establecer vínculos con la UCD:

El proceso de descomposición de la USO viene, por un lado, porque las deudas nos comen, las ayudas que se habían pedido no llegan y, entonces, se crean conflictos de intereses entre las Federaciones: 'Entonces, yo tengo más dinero que tú'. 'Nosotros vamos en avión, tal y cual'. Porque, nosotros, en años anteriores, habíamos utilizado la CNS [Central Nacional Sindicalista, es decir, sindicato vertical] como una conquista de locales y de asistencias permisivas para los trabajadores de siempre (...) La UCD, a través de uno de los partidos catalanes, Adolfo Suarez, le ofrece a Zaguirre pagar los 15 millones de pesetas que debía. Se hizo un Consejo General y fue desastroso, la gente salió defraudada. Con el entusiasmo con el que entraron la gente en la USO. Con lo que pasamos. Él dijo que la USO no tenía perspectivas de futuro y que nos fuéramos con él a la UGT. Decía que estábamos en la ruina y que no podíamos (GONZÁLEZ, 2016, entrevista oral).

A partir de la expulsión, una parte de la militancia gaditana se plantea seguir con la lucha sindical, pero a través de otro instrumento, otra plataforma desde la que se unieron muchos de los anteriores militantes de la USO. En 1979, se reúne un pequeño círculo de militantes (los hermanos Gaitero, Pedro de Tena y Juan Conde) en Zahara de la Sierra y fundan la Confederación Libre y Autónoma de Trabajadores (CLAT), que sigue fiel al principio de autonomía sindical de la USO originaria. 
Efectivamente, la CLAT organizó a una buena parte de la militancia de la USO bajo una identidad parecida, que estaba basada en los principios de independencia, de la autonomía y de la autogestión. Su principal implantación, al igual que la USO, se concentró en el sector bodeguero y en la construcción naval. En la construcción Naval, los militantes, inicialmente, constituyeron legalmente el sindicato Autonomía Sindical, pero, posteriormente, se integraron a la CLAT con las siglas CAT (Colectivo Autónomo de Trabajadores de la construcción naval), que también tuvo fuerte presencia en el astillero de Manises (Valencia) y, aún hoy, sigue estando presente en el comité de empresa del astillero de Puerto Real. En el sector bodeguero constituyeron el Sindicato Autónomo de la Vid (SAVID), que llegaría a ser hegemónico en el sector, llegando a afiliar a alrededor de 1.800 trabajadores en sus mejores momentos.

El cambio en la estrategia de acumulación capitalista hacia el modelo propio de la etapa de globalización tuvo como hito, en España, la entrada en la Comunidad Económica Europea, en 1986, que vino acompañado de un proceso de reconversión industrial que constituyó la destrucción de empleo en sectores como el bodeguero y la construcción naval (FLORIDO; GUTIÉRREZ; ROCA, 2009). La dura reconversión del sector bodeguero y los fuertes apoyos institucionales y empresariales, que tuvieron las CCOO y la UGT, propiciaron una crisis en el SAVID sindicato. En 1987, convocaron un congreso extraordinario en el que decidieron disolverse. La mayoría de la militancia decidió integrarse en las $\mathrm{CCOO}$, con quien habían desarrollado más afinidad en las luchas por los convenios y contra la reconversión, y a quien veían como un sindicato más autónomo respecto al PCE, desde que Antonio Gutiérrez fuese elegido Secretario General, en 1987. Otro sector optó por integrarse en la CNT jerezana (sector V Congreso) que, en 1989, pasaría a denominarse CGT. En el sector de la construcción naval, el cierre del astillero de Manises, en 2006, y la pérdida de empleo en los astilleros gaditanos han llevado al CAT a tener, hoy, una presencia testimonial. Los otros sindicatos autónomos que integraron la CLAT, también, desaparecieron. 


\section{Conclusiones}

A lo largo de este artículo se ha reconstruido, principalmente, a partir de fuentes orales la trayectoria de la USO en la provincia de Cádiz, en el periodo comprendido entre 1976 y 1981. En primer lugar, se ha contextualizado históricamente y geográficamente los orígenes y la evolución de dicho sindicato en la provincia de Cádiz, durante el tardofranquismo. Se ha hecho referencia a la lucha en la clandestinidad, la infiltración en el sindicato vertical, la cobertura de un sector de la Iglesia católica y el desarrollo de un marco de referencia en torno a las ideas de autonomía sindical y del socialismo autogestionario, que fueron los pilares de la identidad de su militancia. Todo ello, en un contexto de transformación capitalista que ha sido marcado desde el paso brusco de una economía autárquica y un sistema corporatista de relaciones laborales, hasta una economía liberalizada e insertada en los circuitos globales de capital, con el consiguiente debilitamiento del poder sindical y con la desaparición de la protección estatal.

Posteriormente, este trabajo se ha centrado en el desarrollo de la USO en los dos sectores de mayor implantación en la provincia de Cádiz: la construcción naval, en la zona de la Bahía de Cádiz y el sector bodeguero, en el Marco de Jerez. En estos sectores particulares que concentraban una gran fuerza de trabajo, la USO contó con importantes líderes que llevaron a cabo un trabajo fundamental de organización y movilización, primero desde el interior del Sindicato Vertical y, ya en democracia, a través de organizaciones sindicales que eran legalizadas. Así, la USO que, posteriormente, dio lugar a otros sindicatos autónomos durante los primeros años de democracia, logró la mayoría en el comité de empresa del astillero de Puerto Real (aunque las CCOO eran mayoritarias en la empresa auxiliar) y en el conjunto del sector bodeguero del Marco de Jerez. Desde esta posición, la USO y sus sindicalistas desempeñaron un papel fundamental en las movilizaciones contra los procesos de reconversión industrial en dichos sectores, que comenzaron a finales de la década de 1970 y se intensificarían, posteriormente, en la década de 1980.

Por último, el artículo ha analizado las tensiones internas que dieron lugar a la expulsión de la federación territorial de Cádiz de la USO, en 1978, y la posterior constitución de sindicatos autónomos, que fueron integrados en la CLAT. A partir de las 
daba la circunstancia de que la mayor parte de los líderes del sindicato en Cádiz, en 1978, pertenecían a la corriente socialista autogestionaria, defensora de la autonomía sindical. Así, frente a los intentos de los dirigentes nacionales por que la USO participara en el intercambio político, bien integrándose a la UGT, bien vinculándose con la UCD, el sector autogestionario mostró abiertamente su oposición, defendiendo un modelo sindical autónomo. Este conflicto interno se saldó con la expulsión de toda la federación. Numerosos líderes sindicales, no obstante, bien arraigados en determinadas industrias y empresas de la provincia, decidieron constituir sus propios sindicatos, como el SAVID en las bodegas y el CAT en la construcción naval.

Estos sindicatos autónomos tendrían -la mayoría- una vida efímera, aunque, indudablemente, un fuerte impacto en la historia social de las localidades de la provincia de Cádiz en determinados momentos, especialmente en los episodios de resistencia a los procesos de reconversión industrial, que en la zona afectaron con especial dureza al sector de la construcción naval y al bodeguero. A pesar del silencio historiográfico sobre la USO gaditana en dicho periodo, la historia social y política de la provincia de Cádiz no puede entenderse sin tener en cuenta el papel de su militancia.

\section{Referencias}

ALMENDROS MORCILLO, Fernando. El sindicalismo de clase en España (1939-1977).

Barcelona: Península, 1978.

CRUZ, Joaquín. Entrevista cedida a Beltrán Roca. Puerto Real, 2008.

EL SECTOR RADICAL DE USO ACUERDA SU INTEGRACIÓN EN COMISIONES OBRERAS. EI

País, Madrid, 08 mar. 1980.

FLORIDO, David; GUTIÉRREZ, José Luis; ROCA, Beltrán. El pueblo en la calle: Reconversión naval, sindicalismo y protesta popular en el astillero de Puerto Real. Sevilla: Fundación Centro de Estudios Andaluces, 2009. 
FLORIDO, David; ROCA, Beltrán; GUTIERREZ, José Luis. Tightening the screws. Autonomy, collective action and violence in the shipyard of Puerto Real during the second shipbuilding restructuring. Anthropological Quarterly, Washington, n.86, v.3, p. 891-921, 2013.

FOWERAKER, Joe. La democracia española. Madrid: Arias Montano, 1990.

GAITERO, Pepe. Entrevista cedida a Eva Bermúdez. Jerez de la Frontera, 2016.

GARCÍA CALAVIA, Miguel Ángel. Relaciones laborales en Europa Occidental. Valencia: Tirant lo Blanch, 2012.

GÓMEZ, Pepe. Entrevista cedida a Beltrán Roca. Puerto Real, 2008.

GONZÁLEZ, Sebastián. Entrevista cedida a Eva Bermúdez y Beltrán Roca. Jerez de la Frontera, 2016.

IGLESIAS, Ignacio. Firmas en Informaciones. Las corrientes sindicales en España. Unión Sindical Obrera (USO). Informaciones, Madrid, 19 ago. 1976.

MEDINA GARCÍA POLAVIEJA, Jesús. Discurso de Jesús Medina García de Polavieja para su ingreso en la Academia de las artes, las ciencias y las letras de San Dionisio de Jerez. Jerez de la Frontera: Academia San Dionisio, 2014.

MELLADO MORALES, Juan de Dios. 1973-1983 Crónica de un sueño: memoria de la transición democrática en Cádiz. Sevilla: Centro de Estudios Andaluces, 2004.

MILLÁN CHIVITE, José Luis. Cádiz en el siglo XX. En: LOMAS SALMONTE, Francisco Javier (Ed.). Historia de Cádiz. Madrid: Silex Ediciones, 2005, p. 889-890.

MONTES PITA, Luis. Conflictos e ideología en la Unión Sindical Obrera antes y después de la escisión de 1980. En: En: QUIROSA.CHEYROUZE, Rafael (Ed.). Historia de la Transición en España: sociedad y movimientos sociales. Almería: Universidad de Almería, 2009, p. 271-294.

OLIET PALÁ, Alberto. La concertación social en la transición. La génesis de un modelo de intercambio. Espacio, tiempo y forma. Serie V, Historia contemporánea, Madrid, n.13, p. 441-482, 2000.

ORGANIZACIONES SINDICALES. A partir de las 12 de la mañana se abrió el registro. UGT, CCOO y USO, legalizadas (También quedaron inscritas SOC y STV). Arriba, Madrid, 29 abr. 1977. 
PÉREZ DE GUZMÁN, Sofía. Negociación colectiva, acción sindical e intercambio político. Un planteamiento teórico apoyado en el análisis de las relaciones laborales en los astilleros de Cádiz. Papers: Revista de Sociología, Barcelona, n.97, v.4, p. 773-794, 2012.

PÉREZ GIL, Pepe. Entrevista cedida a Eva Bermúdez y Beltrán Roca. El Puerto de Santa María, 2016.

PÉREZ SERRANO, Julio. Implantación y representación de UGT Andalucía en el medio rural. En: PÉREZ SERRANO, Julio (Dir.). La aportación de UGT Andalucía al medio rural andaluz: de la reforma agraria al desarrollo rural. Sevilla: Fundación para el Desarrollo de los Pueblos de Andalucía, 2010, p. 35-73.

PÉREZ SERRANO, Julio. Orto y ocaso de la izquierda revolucionaria en España (1959-1994). En: QUIROSA.CHEYROUZE, Rafael (Ed.). Los partidos en la Transición: las organizaciones políticas en la construcción de la democracia española. Madrid: Biblioteca Nueva, 2013, p. 249-291.

PIÑEIRO BLANCA, Joaquín. El motor del cambio: asociacionismo y sociabilidad en la provincia de Cádiz, 1973-1983. En: QUIROSA-CHEYROUZE, Rafael (Ed.). Historia de la Transición en España: sociedad y movimientos sociales. Almería: Universidad de Almería, 2009, p. 345-378.

REYES MATE, Manuel. Una interpretación histórica de USO: Por un socialismo autogestionario. Madrid: Carlos Oya, 1977

ROCA, Beltrán; FLORIDO, David. Narrativas de la reconversión: historias de vida, memoria social y acción colectiva en el astillero de Puerto Real. Revista de Dialectología y Tradiciones Populares, Madrid, n.70, v.1, p. 11-33, 2015.

ROMÁN ANTEQUERA, Alejandro. Movimientos sociales y conflictividad en la provincia de Cádiz durante la Transición. 1975-1985. En: QUIROSA-CHEYROUZE, Rafael (Ed.). Historia de la Transición en España: sociedad y movimientos sociales. Almería: Universidad de Almería, 2009, p. 393-416.

SÁNCHEZ RECIO, Glicerio. El Sindicato Vertical como instrumento político y económico del régimen franquista. Pasado y Memoria. Revista de Historia Contemporánea, Alicante, n.1, p. 1-37, 2002.

SERRANO, Rodolfo. José María Corell y otros dirigentes de los socialistas de Comisiones Obreras se pasan a UGT. El País, Madrid, 24 nov. 1985.

SERVICIO CENTRAL DE DOCUMENTACIÓN (SECED). Unión Sindical Obrera (USO). [s.I.:s.n.], 1975. Col. Grupos Subversivos Clandestinos, 10. 
SNOW, David; BENFORD, Robert. Ideology, Frame Resonance, and Participant Mobilization. En: KLANDERMANS, Bert; KRIESI, Hanspeter; TARROW, Sidney (Eds.). From Structure to Action: social movement participation across cultures. Greenwich: JAI Press, 1988, p. 197-217.

SOLER, Marta. La vitivinicultura del Marco de Jerez en la globalización 1980-2004. En: ETXETARRETA, Mikel (Coord.). La agricultura Española en la era de la globalización. Madrid: Centro de Publicaciones del Ministerio de Agricultura y Pesca, 2006, p. 563-613.

TORRES BARRANCO, Francisco Javier. Los movimientos obreros especializados de acción católica de la diócesis de Cádiz: JOC y HOAC. Una aproximación histórica y apostólica, Trocadero, Cádiz, n.27, p. 101-121, 2015.

TRABAJADORES DE LA VID DE JEREZ BUSCAN SOLUCIÓN A SU CONFLICTO EN MADRID. El País, Madrid, 03 abr. 1979. 